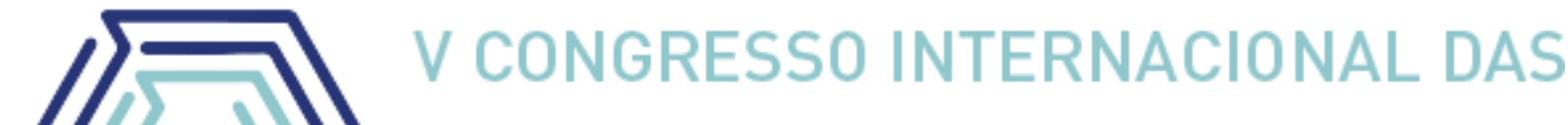 LICENCIATURAS COINTER - PDVL 2018
}

\section{O PROCESSO DE APRENDER NA PERCEPÇÃO DO ALUNO}

\section{THE LEARNING PROCESS IN THE STUDENT'S PERCEPTION}

Pedro Henrique Alves Amorim ${ }^{1}$; Teresinha Vilani Vasconcelos de Lima²

DOI: https://doi.org/10.31692/2358-9728.VCOINTERPDVL.2018.00116

\section{Resumo}

A concepção de aprender do aluno ainda está ligada a ideia de obtenção de informação a partir de memorização. O uso e a compreensão do conhecimento devem ter como resultados a organização significativa de atividades propostas, de forma que o processo de aprender resulte em mudanças não só conceituais mais políticas também. Esse estudo realizado com alunos de uma escola pública que oferta ensino médio em Teresina - PI, teve como objetivo entender como estes alunos definem aprender, o que facilita este processo, assim como, de que maneira eles comportam-se durante esse processo. Como instrumento de pesquisa foi utilizado um questionário aberto aplicado com 124 (cento e vinte quatro) alunos. Os resultados encontrados nessa pesquisa apontam que as estratégias de aula expositiva e dialogada, resolução de exercícios e o uso de recursos didáticos é o que lhes dão suporte para um aprendizado mais eficaz, considerando as condições que podem ou não possibilitar a aprendizagem.

Palavras-Chave: Aprendizagem, Estratégias de ensino, Ato de aprender.

\section{Abstract}

The conception of learning of the student is still linked to the idea of obtaining information from memorization. The use and understanding of knowledge must result in a meaningful organization of proposed activities, so that the learning process results in not only conceptual but also political changes. This study carried out with students of a public school offering high school in Teresina - PI, aimed to understand how these students define learning, which facilitates this process, as well as how they behave during this process. As an instrument of research, an open questionnaire

1 Licenciatura em Física, IFPI, pedro.18.1993@gmail.com

2 Especialista em Supervisão Escolar, IFPI, vilani@ifpi.edu.br 
applied with 124 (one hundred and twenty four) students was used. The results found in this research point out that the strategies of expository and dialogic classes, resolution of exercises and the use of didactic resources are what support them for a more effective learning, considering the conditions that may or may not allow learning.

Keywords: Learning, Teachingstrategies, To learn.

\section{Introdução}

Este artigo surgiu a partir de diversos questionamentos sobre o ato de aprender, conduzidos através de pesquisas feitas acerca do tema proposto. Os questionamentos giram em torno de: como ocorre o ato de aprender? Qual a influência das relações interpessoais no aprendizado? Que fatores contribuem para o aprendizado? Que estratégias os alunos utilizam para aprenderem? dentre outros. $\mathrm{O}$ ato de aprender exigem do aluno perpassa pelo conhecimento consciente de como ocorre esse processo, se o individuo é ativo, crítico reflexivo ou apenas receptor durante o processo de aprendizagem.

Para que obtivéssemos resposta a esses questionamentos foi aplicado um questionário,sobre percepção dos alunos sobre o ato de aprender e o processo da construção de sua aprendizagem. A pesquisa aponta como resultado que o ato de aprender era caracterizado pela aquisição do conhecimento acerca do conteúdo, pela aprendizagem adquirida tendo esperado um produto, ou seja, aos exames ou provas, onde aprender exprimem aprendizados em termos de conteúdos de pensamento descontextualizados, de objetos pensáveis em si mesmos, sem referência direta, Charlot (1996). O ato de aprender não é compreendido apenas por alunos, mas também entre muitos professores, que enxergam o conteúdo a ser trabalhado sempre como um produto a ser cobrado, e não como algo que deve ser construído pelo aluno para possa compreender e tornar aquilo aplicável dentro do seu cotidiano. Percebe-se que aprender é um processo que se caracteriza por um conteúdo a ser cobrado pelos professores, independente do processo ensino-aprendizagem.

\section{Fundamentação Teórica}

De acordo Chiarella, et al.(2015) Paulo Freire concebeu a educação como instrumento; onde baseia-se na indissociabilidade dos contextos e das histórias de vida na formação de sujeitos, que ocorre por meio do diálogo e da relação entre aluno e professor. O mesmo 
enfatiza que ambos, professores e alunos, são transformados no processo da ação educativa e aprendem ao mesmo tempo.

Partindo dessa premissa buscamos compreender como o ato de aprender possibilita no indivíduo a oportunidade de construção, aquisição e compreensão do mundo que o cerca, estabelecendo nele e se tornando indispensável à relação de uma construção conceitual crítica. Inicialmente, podemos pensar o ato de aprender e aprendizagem possa ser a mesma coisa, entretanto, ao observarmos estes conceitos sob o olhar de Piaget (1976), Vygotsky (1917), Freire (1996) à luz de outros teóricos que trabalharam esse tema, estes se completam por entenderem que aprender ocorre por meio cognitivo, com ou sem interações sociais e/ou o com o mundo. Charlot (2000), nos fala, não há sujeito de saber e não há saber, senão em uma certa relação com o mundo. Assim, essa relação do sujeito com o saber não permeia apenas por uma relação com o conhecimento e sim como uma relação com entre o próprio sujeito e demais sujeitos que fazem parte dessas interações.

Piaget (1976) nos diz que aprender se concretiza como uma interpretação pessoal do mundo, ou seja, é uma atividade individualizada, um processo ativo no qual o significado é desenvolvido com base em experiências, Vygotsky (1917) diz que é uma experiência social, mediada pela utilização de instrumentos e signos, a qual é mediada pela interação entre a linguagem e a ação e para Freire (1996), aprender é transformar o individuo, torná-lo capaz de ler o mundo, aprender a ler a realidade (conhecê-la) para em seguida poder reescrever essa realidade e transformá-la.

Bernard Charlot (2002), afirma que o aluno é um ser humano, um ser social, um ser singular, assim esse sujeito age no e sobre o mundo, encontra a questão do saber como necessidade de aprender, produzindo a si próprio. Para que o ato de aprender caminhe tendo como base as definiçõos acima, se faz necessário uma prática pedagógica que considere um aluno como um elemento participativo no processo. Pois a prática pedagógica constrói a realidade do aluno e assim se modifica por meio da interpretação coletiva, onde o papel do professor faz-se bastante importante uma vez que o professor deve dialogar com a necessidade do aluno, produzindo o aprendizado no aluno, tornando assim esse aprendizado importante para o aluno, Franco (2012).

Desse modo para ocorrer aprendizagem faz-se necessário às intervenções e/ou metodologias intencionais, processos motivadores e incentivos para o indivíduo aprender, o ato de aprender está ligado intrinsecamente ao conhecimento, com a percepção do mundo que 
o cerca e/ou com um saber previamente adquirido de determinado assunto, facilitando assim o ato de aprender.

Assim, será observado que ao longo desse estudo, que aprender na percepção dos sujeitos da pesquisa o conhecimento se resume em uma apropriação mental, que surge a partir de uma abordagem de conteúdo que dar-se com explicação do mesmo, em que se aprende de forma individualiza através das metodologias de ensino utilizadas pelos professores.

Sabe-se a importância do professor no processo de aprendizagem do aluno, e nesse sentido rever sua prática pedagógica de maneira que, esse tenha um caráter intencional, que não seja limitada apenas dentro da escola, mas também, valorizando a experiência cotidiana desse aluno como forma de transformação na medida em que se torna capaz de responder às necessidades, pois segundo Franco (2012), o professor que sabe qual é o sentido de sua aula para a formação do aluno, que sabe como sua aula integra e expande a formação desse aluno, que tem consciência do significado da própria ação, insistindo assim, na sua aprendizagem, acompanhada pelo seu interesse.

\section{Metodologia}

A pesquisa qualitativa foi utilizada para a realização deste trabalho, com objetivo segundo Creswel (2007) destacar a preocupação com o processo é muito maior do que com o produto, ou seja, o interesse do pesquisador ao estudar um determinado problema é verificar "como" ele se manifesta nas atividades, nos procedimentos e nas interações cotidianas.

E nesse sentido, adotamos um questionário constituído de seis (6) perguntas, constando variáreis que afetam o ato de aprender. Dividido o questionário em um levantamento do perfil dos sujeitos e a percepção do ato de aprender dos alunos de uma escola estadual de Teresina - PI, que oferta o ensino médio. A amostra dos sujeitos foi cento e vinte e quatro (124) estudantes da $1^{\circ}$ a $3^{\circ}$ série do Ensino Médio. Uma carta de consentimento junto a direção, professores e alunos para aplicação do questionário foi aplicado de maneira aleatória para realização da pesquisa.

\section{Resultados e Discussão}

Os sujeitos da pesquisa têm entre 14 e 20 anos, e são estudantes da $1^{\mathrm{a}}, 2^{\mathrm{a}}$ e $3^{\mathrm{a}}$ séries do Ensino Médio de uma escola estadual de Teresina - PI. 


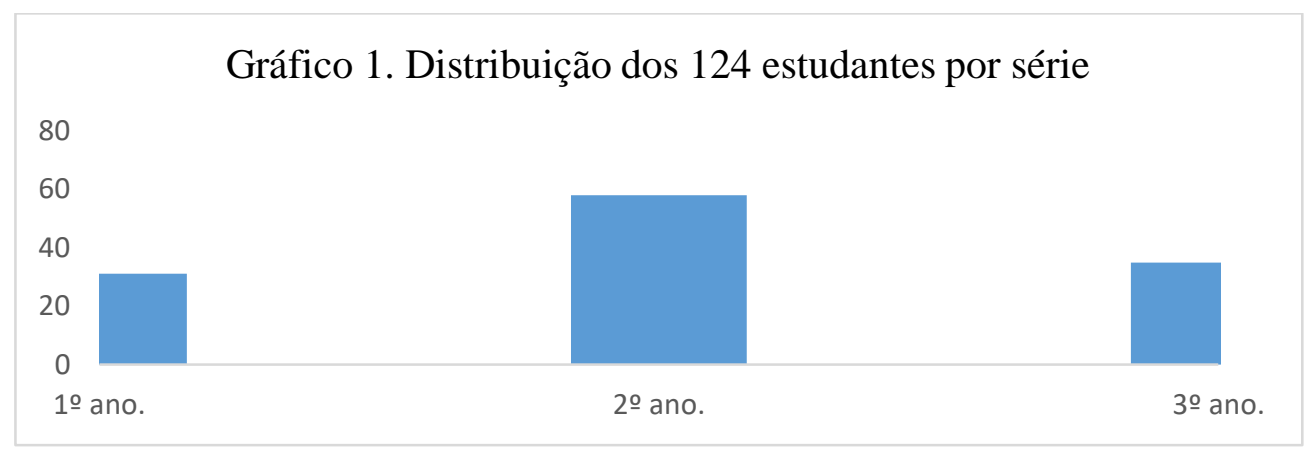

Fonte: Próprios autores

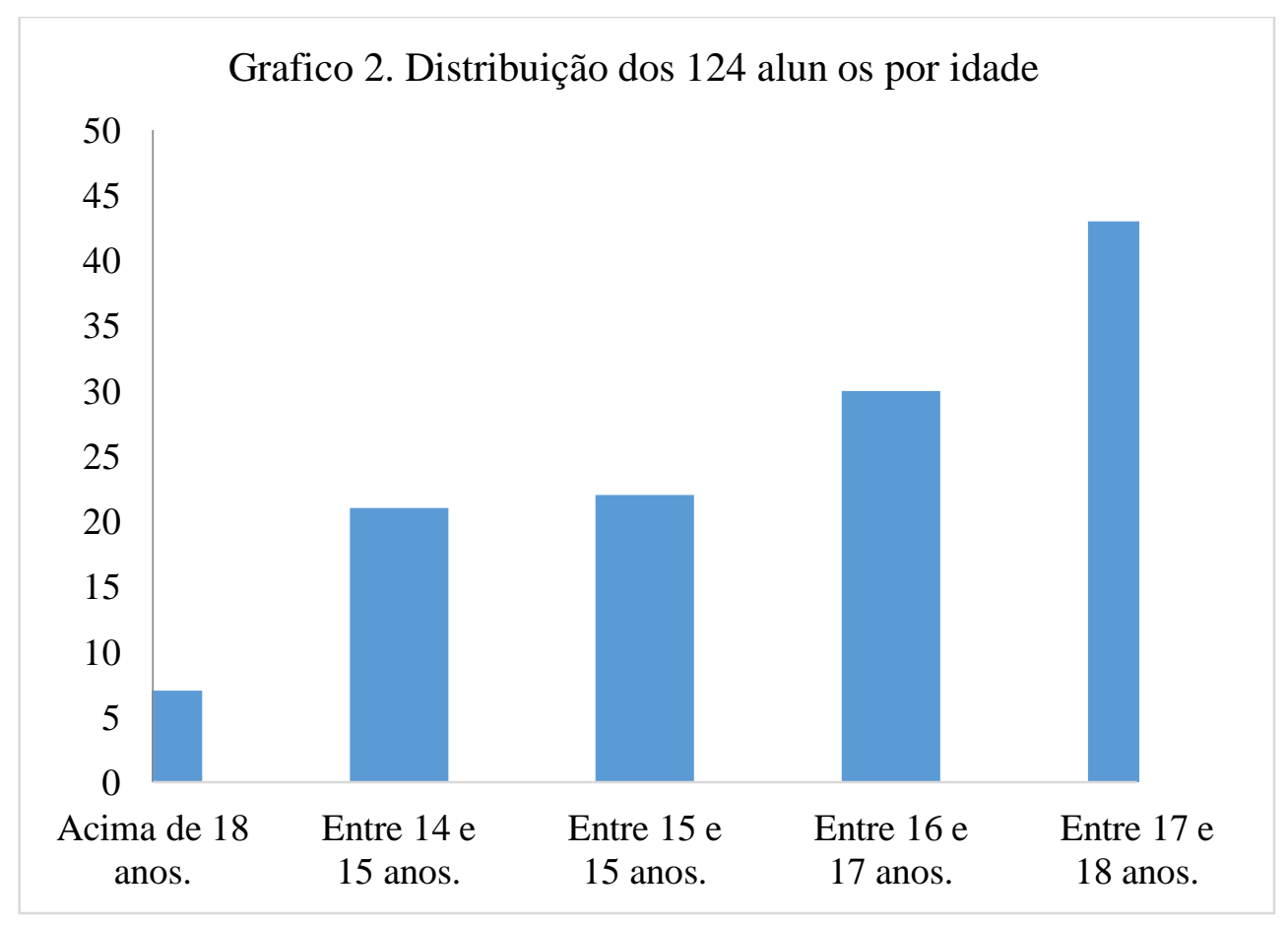

Fonte: Próprios autores

Os resultados aqui apresentados e discutidos, foram considerados a definição de aprender, o que facilita este processo, assim como, de que maneira eles comportam-se durante esse 
processo. Optamos por respeitar a identificação dos sujeitos, representando os alunos com a nomenclatura: A1 - Aluno 1, A2 - Aluno 2 e demais. Em resposta temos:

"Aprender é adquirir conhecimento novo, sobre a vida, ter educação, saber além do que conhece saber algo que não conhece.” A1

“Absorção de algo novo, sendo auxiliado por um professor, não necessariamente dentro de uma sala de aula." A2

"Aprender é levar o que foi ensinado em sala para toda sua vida e se lembrar dele quando o mesmo for citado.”A3

Podemos destacar algumas variáveis nas respostas como: adquirir conhecimento, absorver informações para a vida, capacidade de transmitir conhecimento e a compreensão do assunto abordado pelo professor. Destaca-se que a concepção do "conceito de aprender" se inclui dentro da construtiva proposta por Piaget, onde o mesmo coloca o aluno como indivíduo que aprende a partir da interação entre ele e o meio em que ele vive, construindo a própria concepção do mundo em que vive, a partir de suas próprias experiências, gerando novos modelos mentais e acomodando-as as experiências atuais. Onde o professor é visto como um mediador do conhecimento.

Partindo dessa perspectiva o professor é o mediador do conhecimento, o aluno participa ativamente com ele do próprio aprendizado por meio da experimentação, da pesquisa e discussões em grupo, do estímulo a dúvida e do desenvolvimento do raciocínio, entre outras ferramentas.

Na segunda questão é colocado o que caracteriza aprender? Os sujeitos nos apontaram as seguintes respostas:

"Quando estou em uma situação que envolva algo relacionado aos conteúdos, e lembro-me do que estudei (cotidiano, provas, debates, discussões, entre outros).”A4

"Tirar boas notas." A5

"Caracteriza aquilo que não foi decorado, que não pode ser esquecido com o passar do tempo." A6

"Quando o professor pergunta e eu sei responder de primeira" A7

"A facilidade de responder a atividade proposta pelo professor sobre o conteúdo estudado.” A8

Observa-se que para estes alunos o que caracteriza o aprendizado são situações onde é posto em prática o aprendizado mecânico, onde o aluno deve apenas saber determinado 
conhecimento que foi aprendido, ora quando o mesmo é indagado com uma pergunta pelo professor, ora quando exposto a um exame. E uma parcela dos alunos informa que o processo de aprender foi efetivado quando um conteúdo visto em aula é associado com algum evento do cotidiano. Mas em sua grande maioria é caracterizado o ato de aprender e/ou que aprendeu como uma ameaça, uma vez que este ato é encarado dessa maneira não há qualidade da aprendizagem e nem o estudante se sente apto e a vontade a aprender.

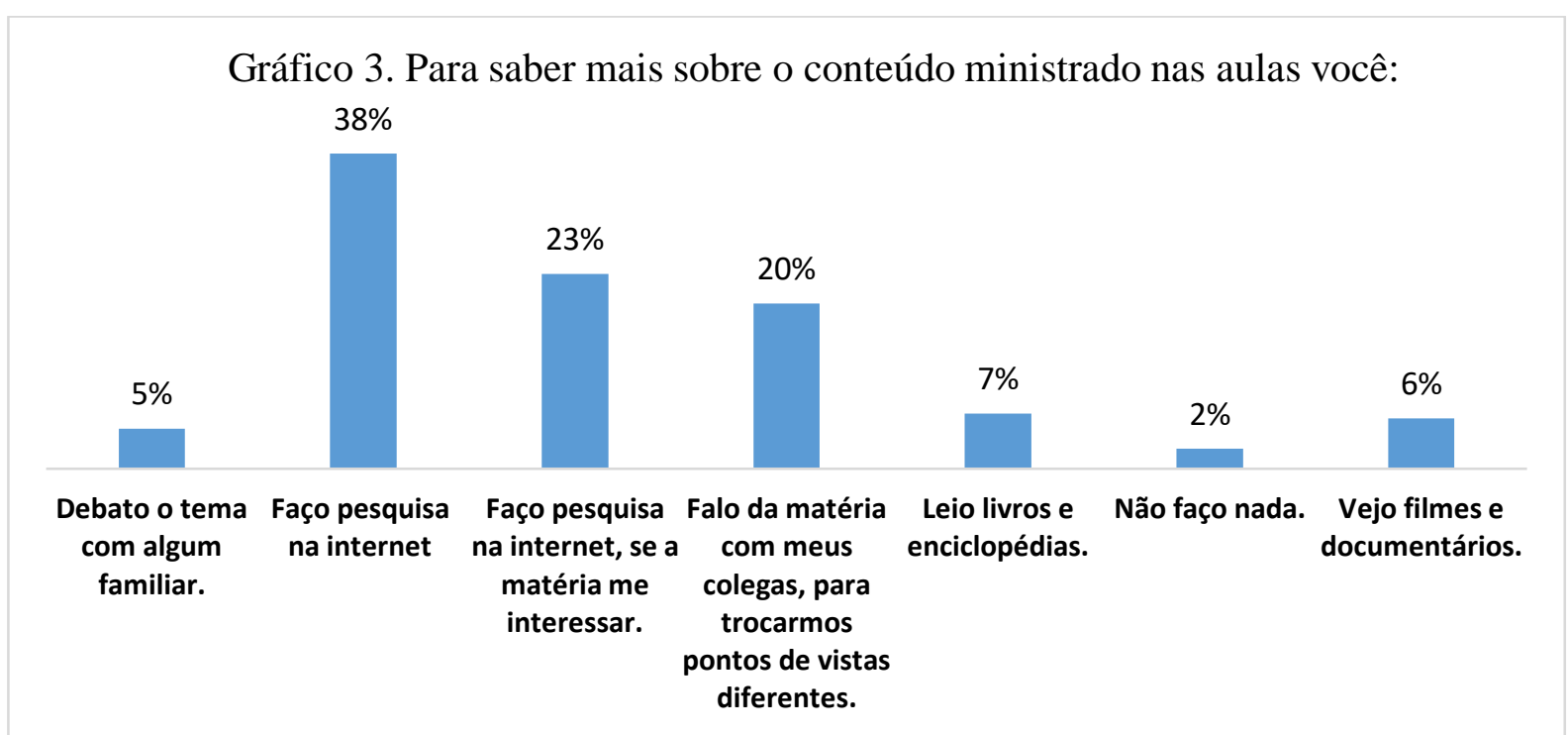

Fonte: Próprios autores

$\mathrm{Na}$ terceira questão é perguntado aos alunos o que fazem para saber mais sobre o conteúdo visto em aula, as respostas mais significativas indicaram que fazem pesquisas na internet, nos atentando ao fato de que muitos destes alunos não se prendem ou se acomodam apenas pelo que veem em sala de aula, buscam algo mais para compreender o que foi exposto em aula entrando em conflito com o público que fazem pesquisa sobre o conteúdo quando este o interessa, demonstrando que quando não há um estímulo nesse aluno o mesmo não se sente a vontade para buscar mais conhecimento, sendo nestes casos o professor pode gerar o estímulo agindo não só como mero transmissor de conhecimento e sim atuando como parceiro, orientando esse aluno e provocando o conhecimento.

Outro grupo de alunos informa que falam da matéria com os colegas, para trocar pontos de vista diferentes do conteúdo ensinado em aula, onde através dessas interações em grupo, o aluno sente-se mais à vontade e apto a consolidar melhor seus conhecimentos a partir de sua ação, sendo capaz de estabelecer as relações ao seu redor e construindo as características do mundo.

$\mathrm{Na}$ quarta questão, é perguntado aos estudantes: que o professor faz para que você 
aprenda com mais facilidade?

Gráfico 4. Em sua opinião você aprende mais facilmente o conteúdo quando o professor:

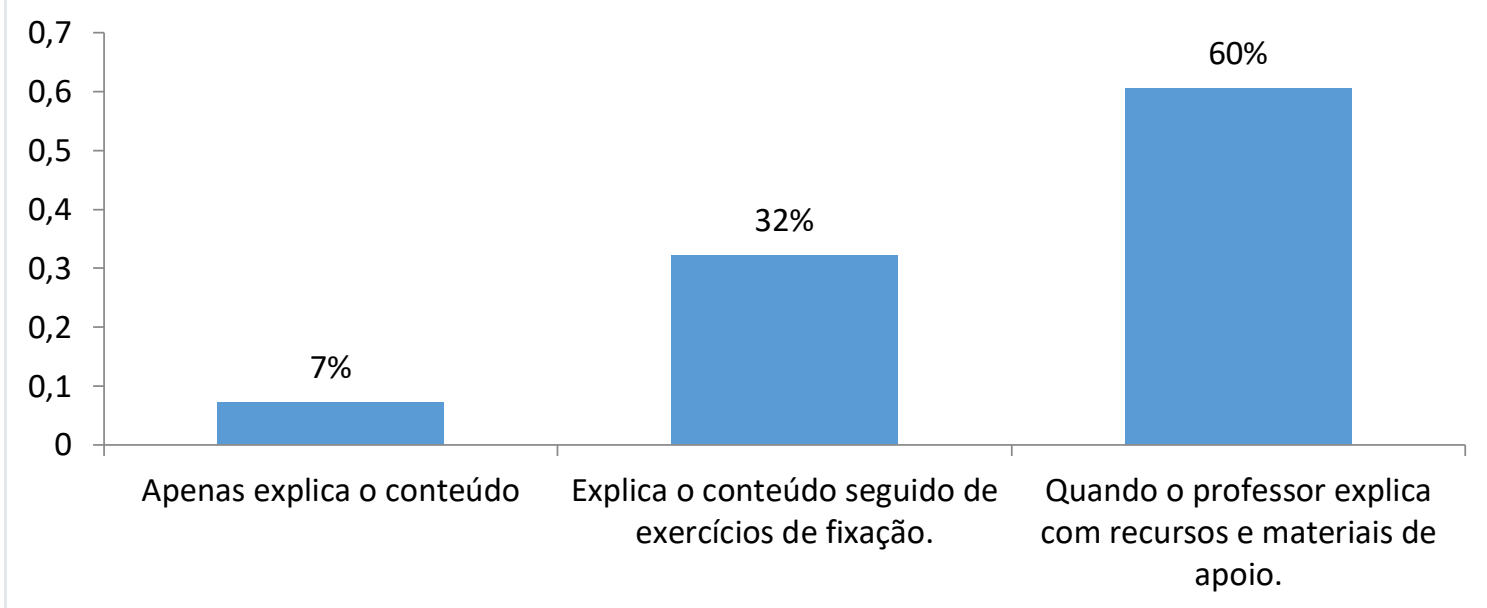

Fonte: Próprios autores

Após análise é perceptível que grande maioria dos alunos aprendem mais quando o professor explica o conteúdo seguido de exercícios, segundo Dante (2003) a resolução de exercícios faz com que o aluno pense de maneira mais produtiva, desenvolva seu raciocínio e o prepare preparar para enfrentar situações novas, pois é evidenciado que é colocando em prática o que foi ensinado que o ato de aprender se concretiza de forma mais eficiente, nos remetendo a uma concepção do que Skinner dizia acerca da aprendizagem: na sala de aula, a repetição mecânica deve ser incentivada, pois esta leva à memorização e assim ao aprendizado.

Além dos estudantes que manifestam aprender mais quando o professor explica o conteúdo seguido de exercício de aplicação cerca de 32,26\% dos alunos informam aprender mais quando o professor explica o conteúdo com uso de recursos de apoio, pois segundo Souza (2007) o uso destes recursos deve servir como motivação aos mesmos, predispor maior interesse pelo conteúdo ministrado e facilitar a compreensão do conteúdo proposto, tornando assim a aula mais interativa, onde os alunos conseguem visualizar o que antes era visto apenas na prática, tornando a aula dinâmica, menos monótona e com mais motivação por parte dos alunos em participar da aula. Tal escolha efetuada por estes alunos pode ser compreendida segundo Costoldi e Polinarski (2009), onde afirmam que o uso destes recursos são de 
fundamental importância no processo de desenvolvimento cognitivo do aluno e deve ter o poder de aproximar o aluno do conteúdo ministrado, facilitando assim sua efetiva fixação.

Com base nessas observações podemos entender um dos motivos que os estudantes responderam que:

"Aprendo mais quando o professor torna a aula mais atrativa, introduzindo o aluno na aula." A9

"Aprendo mais quando o professor traz exemplos do cotidiano." A10

$\mathrm{Na}$ questão cinco foi solicitado que justificassem as escolhas da questão anterior. Sobre o uso de recursos e materiais de apoio os estudantes responderam:

"Acho que é tão quando importante o conteúdo em si quando fazer uso de outros recursos para reforçar a aprendizagem.”A11

"Pois com recursos o professor mostra onde aplicar o conteúdo no dia-a-dia." A12

"Aulas ministradas com recursos e materiais de apoio ajudam a fixar o assunto, pois a aula deixa de ser monótona e vira mais interativa." A13

Ainda sendo a aula expositiva a escolha de muitos professores para explicar um assunto, fazer o uso de materiais de apoio e recurso ainda é uma escolha bastante aceita por parte dos alunos, pois de acordo com Veiga (2006) os métodos e metodologias de ensino devem atender a necessidade dos alunos. Assim tornando o aluno mais próximo da aula permitindo uma interação maior com o assunto, possibilitando que o mesmo visualize determinado conteúdo em seu cotidiano, fazendo assim uma ligação com cotidiano tornando a aprendizagem mais eficiente e ao mesmo tempo mais palpável ao aluno.

Referente a explicar o conteúdo seguido de exercícios de fixação:

"A teoria não consegue ser $100 \%$ eficaz, para aprender é preciso ser testado e questionado, os exercícios são essenciais.” A14

"Porque além do conhecimento do conteúdo tem os exercícios para colocar em prática o que aprendeu." A15

"Porque quando o professor passa exercícios podemos botar em prática o que aprendemos fixando mais ainda." A16

Considerado em sua maioria pelos estudantes os exercícios de fixação constituem uma importante ferramenta de aprendizagem, pois os conteúdos trabalhados em sala são fixados através de exercícios, e segundo os estudantes comprova que realmente aprenderam o conteúdo ministrado, colocando em prática tudo o que foi colocado pelo professor em aula. 
A sexta questão perguntou-se o que facilita o processo de aprendizagem dos alunos durante as aulas, em resposta:

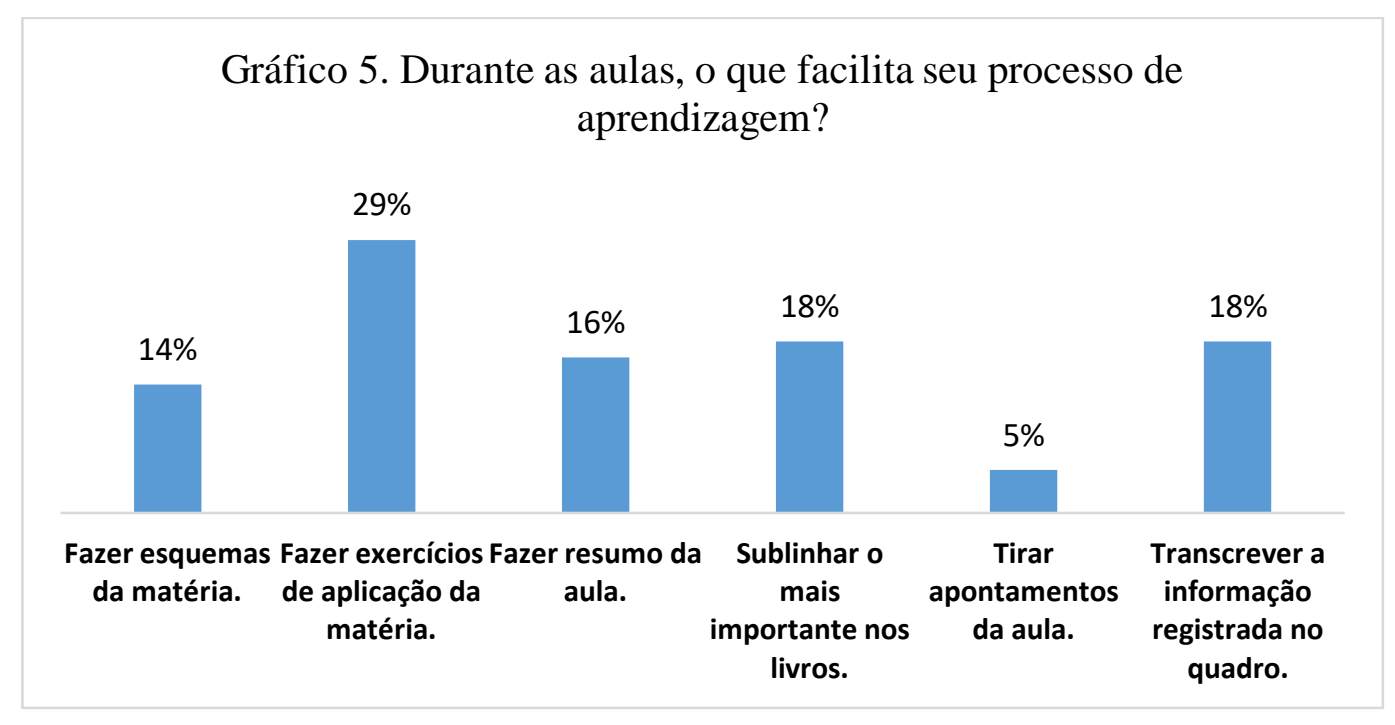

Fonte: Próprios autores

Com base no gráfico, para grande parte dos alunos, o aprendizado se consolida melhor quando é colocado o que foi visto em aula em prática, através dos exercícios- No entanto deve-se ter atenção, pois a resolução de exercícios também deve possibilitar ao aluno desenvolver estratégias, buscar vários caminhos para solucioná-lo à sua maneira, de acordo com sua realidade e raciocínio, colocando uma aplicabilidade em cada exercício resolvido, mostrando que o aluno realmente aprendeu o conteúdo, não apenas para a resolução de exercícios.

\section{Conclusões}

$\mathrm{O}$ ato de aprender se constitui através de vários fatores, intrinsecamente ligados ao aluno, sejam eles referentes a metodologia ou abordagem utilizada pelo professor durante suas aulas ou não.

Apesar de observar que os vários influenciam na aprendizagem do aluno, é evidente, também, que o ato de aprender, apesar de sofrer influência do meio, ou seja, dos diferentes métodos utilizados durante o processo de aprendizagem, e das relações interpessoais, é profundamente individual, uma vez que cada aluno aprende considerando mais agradável de conveniente, no seu próprio tempo.

Assim mesmo que o professor utilize o mesmo método, ou que grande parte dos 
alunos tenha afinidade em aprender determinado conteúdo da mesma maneira, o jeito, o tempo e o ritmo não são, em momento algum, da mesma maneira ao de qualquer outra pessoa, o que torna o ato de aprender individual diante a tanto relatos por parte dos estudantes no decorrer da pesquisa.

Em virtude disso, na percepção destes alunos os mesmos compreendem "aprender" e o ato de aprender como um conhecimento ainda não possuído e partindo disso este aluno desenvolve a capacidade de se apropriar desse conhecimento de acordo com suas próprias possibilidades, desde que tenha as condições necessárias para tal. Dessa maneira, através do questionário levantado para estes alunos para que haja o ato de aprender os professores tem de promover atividades ou/e metodologias que estimulem neste aluno o desenvolvimento desse conhecimento e assim propiciando sua aquisição.

Assim, fica evidente, que aprender na percepção destes estudantes está ligado ao processo cognitivo, o qual promove a assimilação de um novo saber de uma ideia, e a partir disso incentiva e estimula a compreensão do mundo. Sendo através da percepção - um dos processos cognitivos essenciais - que esses estudantes colocam em ordem a informação que recebem dos estímulos externos, seja através de resolução de exercícios, de uma metodologia diferente por parte do professor, reflexão do conteúdo ou a busca de mais informações acerca de determinado conteúdo justamente devido a esse estímulo causado. Ficando evidente, que estes estímulos externos influenciam como a aprendizagem e o "ato de aprender" se comporta em cada aluno.

\section{Referências:}

CHIARELlA, T. et al. A Pedagogia de Paulo Freire e o Processo Ensino Aprendizagem na Educação Médica. Revista Brasileira de Educação Médica, Rio de Janeiro, vol. 39, n. 3, p. 418-425, jul. 2015.

CRESWEL, J. W. Projeto de pesquisa: método qualitativo, quantitativo e misto. 2. ed. Porto Alegre: Artmed, 2007.

CHARLOT, B. Relação com o saber e com a escola entre estudantes de periferia. Cadernos de Pesquisa. São Paulo, 1996.

CHARLOT, B. Da relação com o saber - Elementos para uma teoria. Porto Alegre: Editora Artmed, 2000.

COSTOLDI, R.; POLINARSKI, C.A. Utilização de recursos didático- pedagógicos na 
motivação da aprendizagem. Simpósio internacional de ensino e tecnologia, v. 1, p. 684-69, 2009.

SOUZA, S.E. O uso de recursos didáticos no ensino escolar. I Encontro de Pesquisa em Educação. Arq. Mudi, 11 (Supl.2), p. 10-4, 2007.

VEIGA, I. P. A. Técnicas de ensino: novos tempos, novas configurações. Papirus Editora, 2006

FRANCO, Maria Amélia do Rosário Santoro. Pedagogia e prática docente. / Maria Amélia do Rosário Santoro Franco - 1. ed. - São Paulo: Cortez, 2012. -(Coleção Docência em Formação: Saberes Pedagógicos / coordenação Selma Garrido Pimenta.

DANTE, L. R. Didática da resolução de problemas de Matemática. São Paulo: Ática, 2003. 